\title{
Membangun Kinerja Karyawan Perkebunan BUMN Melalui Pendekatan Iklim Organisasi
}

\author{
RISMAN \\ Sekolah Tinggi Ilmu Ekonomi Riau \\ Jln. HR. Subrantas KM 12 Panam Telp. (0761) 63239 \\ E-mail : risman@lecturer.stieriau.akbar.ac.id
}

\begin{abstract}
The Industrial Revolution 4.0 demands a massive change in employee competency in a company. Not only is the ability in the form of education and skills, it also requires a change in creative and innovative attitudes and risk taking. Employees of plantation companies become a phenomenon, where the current plantation sector, such as the one at PTPN V, still uses relatively large employee workforce and here the company still expects the performance of its employees to sustain company productivity. However, the problem of developing employees is still not optimal and there is even an organizational climate that is still not effectively implemented. Through a quantitative research approach with a sample of as many as 60 people and data collected by questionnaire and analyzed with a simple linear regression analysis tool can it prove that the company can build employee performance through organizational climate improvement. The results of the study prove that through efforts to build a conducive organizational climate the company is able to improve performance in a positive direction. This provides a solution to the problem of the optimal application of employee labor in order to improve company performance.
\end{abstract}

Keywords: Employee Performance, Organizational Climate

Setiap organisasi mempunyai sifat dan karakteristik yang relatif berbeda, begitu juga dengan iklim organisasi antara organisasi yang satu dengan yang lain memiliki perbedaan, dimana keadan internal organisasi akan mempengaruhi tingkah laku mereka yang tergabung dalam organisasi tersebut. iklim organisasi tidak dapat dilihat bahkan disentuh, tetapi dapat dipastikan bahwa iklim itu ada. Pengertian ini dapat digunakan dalam sebuah organisasi yang terdiri individu-individu, berkumpul dan melakukan aktivitas dalam rangka tercapainya tujuan. Maka keberhasilan suatu organisasi ditentukan oleh semua unsur yang membentuk iklim organisasi tersebut. Beberapa instrumen telah dikembangkan untuk mengukur iklim organisasi dan instrumen tersebut secara khas mengidentifikasi sejumlah unsur.

Peran sumber daya manusia merupakan modal dasar dalam penentuan tujuan perusahaan. Tanpa peran sumber daya manusia, kegiatan dalam perusahaan tidak akan berjalan dengan baik. Manusia selalu berperan aktif dan dominan dalam setiap kegiatan organisasi, karena manusia menjadi perencana, pelaku, dan penentu terwujudnya tujuan organisasi (Hasibuan, 2012:10). Tujuan perusahaan akan tercapai bila karyawan memiliki kinerja yang tinggi. Keberhasilan suatu organisasi dalam merencanakan dan melaksanakan strategi ditunjang oleh kinerja para karyawannya.

PT. Perkebunan Nusantara V PKS Sei Pagar Kabupaten Kampar menuntut karyawan agar menyelesaikan tugas dan mampu bekerja dengan penuh semangat guna mencapai target yang ditentukan. Salah satu upaya yang dilakukan adalah dengan menciptakan iklim organisasi yang kondusif. Iklim organisasi merupakan suatu kekuatan sosial yang tidak tampak, yang dapat menggerakkan orang-orang dalam suatu organisasi untuk melakukan aktivitas kerja. Secara tidak sadar tiap-tiap orang di dalam suatu 
organisasi mempelajari situasi yang berlaku di dalam organisasinya.

Berikut adalah tabel jumlah karyawan pada PT. Perkebunan Nusantara V PKS Sei Pagar berdasarkan divisi. Menunjukkan jumlah karyawan pada PT. Perkebunan Nusantara V PKS Sei Pagar Berdasarkan Divisi, dimana jumlah karyawan yang paling banyak adalah berada pada divisi pengolahan yaitu sebanyak 66 orang atau $45.21 \%$.

Berikut data hasil produksi $\mathrm{CPO}$ dalam satuan kilogram (KG) pada PT. Perkebunan Nusantara V PKS Sei Pagar tahun 2013 sampai 2017. bahwa produksi CPO pada PT. Perkebunan Nusantara V PKS Sei Pagar tahun 2013-2017, selama lima tahun terakhir tidak terealisasi $100 \%$ kecuali tahun 2017. Jumlah produksi pada tahun 2013 terealisasi sebesar 93,5\%. Pada tahun 2014 jumlah produksi yang terealisasi sebesar 86,3\%. Tahun 2015 jumlah produksi yang terealisasi hanya sebesar 70,2\%. Tahun 2016 jumlah produksi yang terealisasi dari produksi yang ditargetkan yang tercapai hanya 97,4\% dan tahun 2017 jumlah produksi terealisasi melebihi $100 \%$.

Iklim organisasi sebagai salah satu sistem sosial dipengaruhi oleh lingkungan internal dan eksternal. Lingkungan internal meliputi: desain pekerjaan dan aplikasi teknologi, kultur organisasi dan praktekpraktek manajerial, serta karakteristik anggota. Sedangkan lingkungan eksternal meliputi lingkungan sosial dan ekonomi dimana organisasi berada. Paduan lingkungan eksternal dan internal tersebut akan mempengaruhi kepuasan kerja, produktivitas dan pertumbuhan organisasi.

Menggunakan beberapa teori kinerja dan iklim organisasi serta hasil penelitian terdahulu seperti Satria Ferry (2014) menunjukan bahwa nilai kofisien korelasi variabel iklim organisasi terhadap kinerja karyawan sebesar 0.328 pada kata gori interval rendah. Variabel iklim organisasi berpengaruh positif dan signifikan terhadap kinerja karyawan. Kemudian pendapat Zulkiram (2013) menunjukan bahwa iklim

Jurnal Daya Saing (Vol. 5, No. 1 Februari 2019) organisasi, disiplin kerja dan kompensasi baik secara simultan ataupun parsial berpengaruh terhadap kinerja pegawai lembaga pemasyarakatan kelas IIA Banda Aceh.

Kajian manajemen yang terdiri dari enam unsur (6M) yaitu men, money, methode, materials, machines, dan market. Unsur men (manusia) ini berkembang menjadi suatu bidang ilmu manajemen yang disebut manajemen sumber daya manusia (Hasibuan, 2009). Kemudian Hasibuan (2009) manajmeen sebagai ilmu dan seni. Menurut Rivai dan Ella (2011) Manajemen SDM sebagai ilmu yang mengelola karyawan dan perusahaan. Menurut Flippo dalam Hasibuan (2009) manajemen dimaksudkan terwujudnya tujuan perusahaan, individu, karyawan, dan masyarakat.

Menurut Rivai dan Ella (2011: 13), fungsi manajemen manajerial dan operasional. Berbicara masalah kinerja menurut Wirawan (2009) kinerja adalah keluaran yang dihasilkan oleh fungsi suatu pekerjaan. Menurut Hasibuan (2009) kinerja adalah suatu hasil yang dicapai seseorang dalam melaksanakan tugas-tugas yang dibebankan kepadanya. Menurut Pabundu (2010) seseorang akan selalu mendambakan penghargaan terhadap hasil pekerjaannya dan mengharapkan imbalan yang adil. Menurut Rivai dan Ahmad (2004), kinerja merupakan perilaku nyata yang ditampilkan setiap orang. Siagian (2005:168) mengemukakan kinerja adalah suatu keadaan yang menunjukan kemampuan seorang pegawai dalam menjalankan tugas. Menurut Manullang (2004) kinerja adalah suatu keadaan yang menunjukan banyaknya pekerjaan yang harus dilakukan atau dihasilkan seseorang individu atau sekelompok kerja.

Dari pendapat tersebut dapat dikatakan bahwa kinerja adalah hasil kerja dari fungsi pekerjaan. Faktor yang mempegaruhi kinerja menurut Kasmir (2016) kemampuan dan keahlian; p.ISSN: $2407-800 \mathrm{X} \quad$ e.ISSN: $2541-4356$ 
$\begin{array}{lcc}\text { pengetahuan; } & \text { rancangan } & \text { kerja; } \\ \text { kepribadian; } & \text { motivasi } & \text { kerja; }\end{array}$ kepemimpinan; iklim organisasi; kepuasan kerja; lingkungan kerja; loyalitas; komitmen; disiplin kerja.

Menurut Umam (2010) kontribusi hasil penilaian merupakan suatu yang sangat bermanfaat bagi perencanaan kebijakan organisasi. Indikator kinerja menurut John Miner dalam Sudarmanto (2014), mengemukakan ada 4 dimensi yang dapat dijadikan sebagai tolak ukur dalam menilai kinerja yaitu; Kualitas, yaitu tingkat kesalahan, kerusakan, kecermatan; Kuantitas, yaitu jumlah pekerjaan yang dihasilkan; Penggunaan waktu da bekerja yaitu tingkat ketidak hadiıaı, keterlambatan, waktu kerja efektif/jam kerja yang hilang; Kerjasama dengan orang lain dalam bekerja.

Kemudian teori iklim organisasi menurut Tagiuri dan Litwin (dalam Wirawan, 2007) kualitas lingkungan internal organisasi yang secara relatif terus berlangsung, dialami oleh anggota organisasi; memengaruhi perilaku mereka dan dapat dilukiskan dalam pengertian satu set karakteristik atau sifat organisasi.

Davis (2001) mengungkapkan bahwa iklim organisasi memiliki ciri-ciri organisasi yang penting, dimana dapat dirumuskan beberapa unsur organisasi, untuk mengukur iklim organisasi yaitu dengan mengukur: kualitas Kepemimpinan, kepercayaan, komunikasi, Tanggung Jawab, Imbalan yang Adil, Kesempatan, Pengendalian,

Dengan teori tersebut maka diduga melalui pendekatan iklim organisasi mampu meningkatkan kinerja karyawan perkebunan dalam menopang kinerja perusahaan.

\section{METODE}

Penelitian ini dilakukan pada PT. Perkebunan Nusantara V PKS Sei Pagar yang berada di Desa Hangtuah, Kecamatan Perhentian Raja, Kabupaten Kampar, Propinsi Riau. Waktu penelitian dimulai dari bulan Agustus sampai dengan Desember
2018. Jenis dan sumber data yang penulis gunakan dalam penelitian ini adalah: Data primer, yaitu data yang diperoleh secara langsung dari sumber asli yaitu diperoleh dari karyawan melalui kuesioner.

Pengumpulan data menggunakan kuesioner dengan populasi sasaran dalam penelitian ini adalah seluruh karyawan pada PT. Perkebunan Nusantara V PKS Sei Pagar yaitu sebanyak 146 orang (berdasarkan data karyawan pada bulan Desember 2017) dan sampel se banyak 60 karyawan dengan teknik pengambilan sampel dilakukan secara Convenience sampling, analisa data yang digunakan untuk menjawab pertanyaan-pertanyaan penelitian untuk mengungkap fenomena sosial tertentu. Data yang digunakan adalah data kwantitatif, yaitu data yang berbentuk angka atau bilangan. Sesuai dengan bentuknya, data kuantitatif dapat diolah atau dianalisis menggunakan teknik perhitungan matematika atau statistik dengan alat analisis regresi linier sederhana

\section{HASIL}

Hasil penelitian mengenai pengaruh iklim organisasi terhadap kinerja karyawan pada PT. Perkebunan Nusantara V PKS Sei Pagar Kabupaten Kampar dengan 60 responden diperoleh hasil penelitian setelah dilaukan deskripsi karakteristik responden, deskripsi variabel, uji validitas, uji Reliability, uji normalitas, uji Regresi linear dan uji hipotesa dan determinasi.

Diperoleh hasil dari model regresi yang digunakan dalam penelitian atas variabel independen (iklim organisasi) dengan variabel dependen (kinerja karyawan). Pengolahan data dalam penelitian ini menggunakan linear regresion dengan bantuan program SPSS 23. Berdasarkan analisis regresi dengan bantuan program SPSS seperti terlihat dalam tabel 1berikut ini: 
Tabel 1. Analisis Regresi linear Sederhana

\begin{tabular}{|l|l|l|l|}
\hline \multirow{2}{*}{} & \multicolumn{2}{|l|}{$\begin{array}{l}\text { Unstandardized } \\
\text { Coefficients }\end{array}$} & $\begin{array}{l}\text { Standardized } \\
\text { Coefficients }\end{array}$ \\
\cline { 2 - 4 } Model & B & $\begin{array}{l}\text { Std. } \\
\text { Error }\end{array}$ & Beta \\
\hline $1($ Constant $)$ & 14.3093 .072 & \\
\hline Iklim & .410 & .064 & .646 \\
\hline Organisasi & & & \\
\hline
\end{tabular}

Sumber: Data Olahan, 2018

Berdasarkan hasil analisis regresi sederhana diperoleh koefisien regresi Understandarized Coefficient B maka dapat diperoleh persamaan linear sederhana sebagai berikut:

$\mathrm{Y}=14.309+0,410 \mathrm{X}$

Persamaan regresi linear sederhana diatas dapat dilihat:

1. Nilai konstanta sebesar 14.309 dimana jika iklim organisasi bernilai nol maka kinerja karyawan akan bernilai 14.309 .

2. Variabel iklim organisasi mempunyai pengaruh positif terhadap kinerja karyawan, dengan koefisien menunjukan sebesar 0,410 berarti apabila variabel iklim organisasi meningkat 1 satuan dengan menganggap faktor lain tetap, maka akan meningkatkan kinerja karyawan sebesar 0,410 satuan. Koefisien bernilai positif, artinya ada hubungan positif antara ikilm organisasi dengan kinerja karyawan. Semakin baik iklim organisasi semakin baik pula kinerja karyawan.

Untuk menguji hipotesis dilakukan dengan uji t. Berdasarkan pada hasil perhitungan dengan menggunakan program SPSS 23. diperoleh besarnya nilai koefisien regresi variabel iklim organisasi (X) terhadap kinerja karyawan (Y) dapat dilihat pada tabel berikut ini;

Tabel 2: Uji T (Uji Parsial)

\begin{tabular}{|c|c|c|c|c|c|}
\hline \multicolumn{6}{|l|}{ Coefficients $^{\mathrm{a}}$} \\
\hline \multirow[b]{2}{*}{ Model } & \multicolumn{2}{|c|}{$\begin{array}{l}\text { Unstandardized } \\
\text { Coefficients }\end{array}$} & \multirow{2}{*}{\begin{tabular}{|l} 
Standardized \\
Coefficients \\
Beta
\end{tabular}} & \multirow[b]{2}{*}{$t$} & \\
\hline & $B$ & Std. Error & & & Sig. \\
\hline 1(Constant) & 14.309 & 3.072 & & 4.685 & 5.000 \\
\hline \begin{tabular}{|l} 
Iklim \\
Organisasi
\end{tabular} & .410 & .064 & .646 & 6.44 & 1.000 \\
\hline
\end{tabular}

Sumber : Data Olahan, 2018

Berdasarka tabel 2 di atas dapat maka dapat dibuktikan kebenaran hipotesis yang penulis ajukan secara parsial untuk variabel iklim organisai terhadap kinerja karyawan dengan ketentuan sebagai berikut:

a. Formula Hipotesis

Ho : Tidak ada pengaruh iklim organisasi (X) terhadap kinerja karyawan (Y) pada PT. Perkebunan Nusantara V PKS Sei Pagar Kabupaten Kampar

Ha : Ada pengaruh iklim organisasi (X) terhadap kinerja karyawan (Y) pada PT. Perkebunan Nusantara V PKS Sei Pagar Kabupaten Kampar.

b. Menentuka level of signifikan $\alpha=$ 0,05 dengan derajat kebebasan $(\alpha$ $/ 2$; n-k) $=0,05 / 2 ; 60-1=0,025: 59=$ 2.001 .

c. Kriteria pengujian

Ho: diterima Jika $\mathrm{t}$ hitung $\leq \mathrm{t}$ tabel dan nilai probabilitas $>0,05$

Ho: ditolak Jika $\mathrm{t}$ hitung $\geq \mathrm{t}$ tabel dan nilai probabilitas $<0,05$

d. Nilai $t_{\text {hitung }}$ dan probabilitas

Nilai $\mathrm{t}$ hitung variabel iklim organisasi $=$ 6.441 dan nilai probabilitas 0,00

e. Kesimpulan

Dengan membandingkan $\mathrm{t}$ hitung dan $\mathrm{t}$ tabel diketahui bahwa $\mathrm{t}$ hitung $>\mathrm{t}$ tabel $(6.441>$ 2.001) dan probabilitas $(0,000)<0,05$. Maka untuk variable iklim organisai secara parsial berpengaruh signifikan terhadap kinerja karyawan. Artinya Ho ditolak dan menerima Ha.

Analisis ini digunakan untuk mengetahui seberapa besar sumbangan yang diberikan variabel bebas (iklim organisai) terhadap variabel terikat (kinerja karyawan) yang ditunjukkan dalam persentase. Apabila nilai $\mathrm{R}$ mendekati +1 maka secara bersama-sama variabelvariabel bebas tersebut mempunyai hubungan positif yang cukup kuat. Berikut hasil pengolahan data dengan menggunakan bantuan SPSS 23 diperoleh nilai $\mathrm{R}=0,646$ positif artinya budaya organisai (X) berpengaruh positif pada kinerja karyawan (Y). $\mathrm{R}$ Square $=0,417$ artinya iklim organisai (X) memberi kontribusi sebesar 41,7 \% terhadap kinerja karyawan dan sisanya sebesar 58,3\% dipengaruhi oleh 
variabel lain yang tidak dibahas di dalam penelitian ini.

\section{PEMBAHASAN}

Berdasarkan hasil penelitian dan analisis data serta pembahasan yang telah diuraikan di atas, maka hasil penelitan tentang pengaruh iklim organisasi terhadap kinerja karyawan pada PT. Perkebunan Nusantara V PKS Sei Pagar Kabupaten Kampar ditemukan beberapa temuan penelitian bahwa terdapat pengaruh yang signifikan iklim organisasi terhadap kinerja karyawan pada PT. Perkebunan Nusantara V PKS Sei Pagar Kabupaten Kampar. Hal tersebut dapat dilihat dari hasil perhitungan uji t. dimana $t_{\text {hitung }}>t_{\text {tabel }}(6.441<2.001)$ dan probabilitas $(0,000<0,05)$.

Dari hasil $\mathrm{R}^{2}$ maka sumbangan variabel iklim organisasi (X) mempengaruhi variabel kinerja karyawan (Y) sebesar 41,7\% dan sisanya sebesar 58,3\% dipengaruhi oleh variabel lain yang tidak diteliti dalam penelitian ini.

Hasil analisis deskriptif secara keseluruhan nilai rata-rata (mean) instrumen variabel iklim organisasi pada PT. Perkebunan Nusantara V PKS Sei Pagar Kabupaten Kampar sebesar hal ini menunjukkan bahwa responden secara total rata-rata sebesar 4.00 berada pada kriteria tingkat skala "setuju". Dan secara keseluruhan nilai rata-rata (mean) kinerja karyawan pada PT. Perkebunan Nusantara V PKS Sei Pagar Kabupaten Kampar sebesar 4,25 hal ini menunjukkan bahwa secara total rata-rata berada pada kriteria tingkat skala "setuju”.

Setelah melihat hasil analisis dan kesimpulan yang telah penulis kemukakan di atas, maka selanjutnya maka solusi yang dapat diberikan dalam rangka meningkatkan kinerja karyawan perkebunan melalui iklim organsiasi yakni dari 12 item pernyataan pada variabel iklim organisasi pada PT. Perkebunan Nusantara V PKS Sei Pagar Kabupaten Kampar ditemukan bahwa nilai rata-rata yang paling minimum adalah tentang dalam pekerjaan karyawan tidak mengandalkan orang lain. Untuk itu diharapkan pimpinan memberikan motivasi dan arahan-arahan kepada karyawan agar dalam bekerja tidak mengandalkan orang lain dan harus bertanggung jawab atas tugas yang dibebankan kepadanya.

Pada variabel kinerja karyawan yang perlu menjadi perhatian perusahaan berdasarkan hasil kuesioner yang disebar kepada responden adalah mengenai tingkat pencapaian jumlah kerja sesuai dengan harapan pimpinan. Dalam hal ini peneliti menyarankan agar pimpinan menjalin komunikasi dua arah yang baik dengan karyawan.

Peneliti selanjutnya diharapkan dapat lebih variatif mengembangkan faktorfaktor yang mempengaruhi kinerja karyawan. tidak sebatas pada iklim organisasi, tapi dapat mengembangkan faktor-faktor lainnya seperti kompensasi, kepemimpinan, pengembangan karier, kompetensi dan lain sebagainnya.

Hasil penelitian ini mendukung pendapat Satria Ferry (2014) menunjukan bahwa nilai kofisien korelasi variabel iklim organisasi terhadap kinerja karyawan sebesar 0.328 pada kata gori interval rendah. Variabel iklim organisasi berpengaruh positif dan signifikan terhadap kinerja karyawan. Kemudian pendapat Zulkiram (2013) menunjukan bahwa iklim organisasi, disiplin kerja dan kompensasi baik secara simultan ataupun parsial berpengaruh terhadap kinerja pegawai lembaga pemasyarakatan kelas IIA Banda Aceh.

\section{SIMPULAN}

Berdasarkan uraian di atas, maka dapat disimpulkan bahwa Hasil penelitian membuktikan bahwa melalui upaya membangun iklim organisasi yang kondusif perusahaan mampu meningkatkan kinerja ke arah positif. Hal ini memberikan solusi pada persoalan penerapan tenaga kerja karyawan secara optimal dalam rangka perbaikan kinerja perusahaan. 


\section{DAFTAR RUJUKAN}

Agus Riyanto. 2009 Aplikasi Metodologi Penelitian Kesehatan. Yogyakarta : Nuha Medika.

Asmar, Zul. 2004. Pengaruh Iklim Organisasi dan Motivasi Kerja Terhadap

Kinerja Pegawai Administrasi di FPMIPA UPI. Bandung : UPI

Arikunto, Suharsimi. 2010 Prosedur Penelitian : suatu Pendekatan Praktik. Cetakan Ketigabelas. Jakarta: PT. Rineka Cipta

Davis dan Newstrom. 2000. Prilaku Dalam Organisasi. Jakarta : Erlangga.

Hasan, M. Iqbal, 2002. Pokok-pokok Materi Metodologi Penelitian dan Aplikasinya, Ghalia Indonesia, Bogor

Hasibuan, Malayu, SP. 2012, Manajemen Sumber Daya Manusia, edisi revisi, Bumi Aksara, Jakarta.

Hofstede, 2007. Cultures and organizations software of the mind. New York.

Hartono, 2012, Metodologi Penelitian bisnis, BPFE, Yogyakarta

Kasmir, 2016. Manajemen Sumber Daya Manusia (Teori dan Aplikasi). Edisi 1. Cetakan 1. Jakarta.

Martini, Yulianto R. 2003. Komitmen Organisasi Ditinjau Berdasarkan Iklim Organisasi dan Motivasi Berprestasi. Jurnal Phronesis Vol 5 No.9.

Satria Ferry , 2014. Pengaruh iklim organisasi terhadap kinerja karyawan pada PT. Astra Daihatsu Pekanbaru. Universitas Islam Riau
Tampubolon. 2004. Manajemen Operasional. Jakarta : Ghalia Indonesia

Mangkunegara, Anwar Prabu. 2001. Manajemen Sumber Daya Manusia Perusahaan. Bandung : PT Remaja Rosdakarya

Manullang, M, 2004. Dasar-Dasar Manajemen, Cetakan Ketujuh Belas, Gadjah Mada University Press, Yogyakarta.

Zulkiram. 2013. Pengaruh iklim organisasi, disiplin kerja dan kompensasi terhadap kinerja pegawai serta dampaknya pada kinerja lembaga permasyarakatan kelas IIA Banda Aceh, Aceh

Robbins, Stephen P. 2008. PrinsipPrinsip Perilaku Organisasi. Diterjemahkan oleh Halida. Edisi kelima, Penerbit Erlangga, Jakarta

. 2010. PrinsipPrinsip Perilaku Organisasi. Diterjemahkan oleh Halida. Edisi kelima, Penerbit Erlangga, Jakarta

. 2006. Prinsip-Prinsip Perilaku

Organisasi. Jakarta: Erlangga

. 2002. Perilaku Organisasi Edisi Kelima. Jakarta: Erlangga.

Rochaety, E, dkk. 2007. Metodologi Penelitian Bisnis: Dengan Aplikasi SPSS, Edisi Pertama. Penerbit Mitra Wacana Media : Jakarta.

Riduwan (2010), Metode dan Teknik Menyusun Tesis, Alfabeta, Bandung

Veithzal, Rivai dan Fawzi, Ahmad. 2004. Performance Appraisal. Jakarta : PT RajaGrafindo Persada. 
.2014. Performance Appraisal. Jakarta : PT RajaGrafindo Persada.

Siagian, Sondang P. 2005. Manajemen Sumber Daya Manusia.: Bumi Aksara: Jakarta
_2002. Kiat Meingkatkan Produktivitas Kerja. Rineka Cipta : Jakarta.

Sugiyono. 2010. Metode Penelitian Bisnis. Bandung: Alfabeta . 2013. Metode Penelitian Bisnis. Bandung: Alfabeta.

Sujarweni, Wiratna.(2014). SPSS Untuk Penelitian, Baru Press, Yogyakarta

Umam, Khaerul . 2010. Perilaku Organisasi. Bandung: CV Pustaka Setia

Wibowo. 2006. Manajemen Kinerja. Jakarta : PT RajaGrafindo Persada

Wirawan .2009. Evaluasi Kinerja Sumber Daya Manusia: Teori Aplikasi dan Penelitian, Jakarta Salemba Empat.

Wirawan. 2007. Budaya dan Iklim Organisasi. Jakarta : Salemba Empat. 